\title{
Quality changes of shrimp cracker covered with fish gelatin film without and with palm oil incorporated during storage
}

\author{
Krisana Nilsuwan - Soottawat Benjakul • Thummanoon Prodpran
}

Received: 24 March 2016/Accepted: 2 July 2016/Published online: 22 July 2016

(C) The Author(s) 2016. This article is published with open access at Springerlink.com

\begin{abstract}
Impact of fish gelatin film incorporated without and with palm oil on the quality changes of fried shrimp cracker stored for 15 days at room temperature was investigated, in comparison with nylon/linear lowdensity polyethylene (nylon/LLDPE) film. The moisture content and water activity of shrimp cracker packaged with all films increased during storage $(p<0.05)$. The lowest moisture content and water activity were found in the sample packaged with nylon/LLDPE film throughout the storage $(p<0.05)$. Sample packaged with fish gelatin films incorporated with palm oil generally had lower moisture content than those without oil added during the first 12 days of storage $(p<0.05)$. During 15 days of storage, shrimp cracker packaged with nylon/LLDPE film generally had the lower PV and TBARS value as well as volatile compounds, except for $n$ nonanal, than those stored in fish gelatin films, regardless of oil incorporation. The decrease in crispiness and increase in toughness occurred in all samples during the 15 days of storage. Nevertheless, the lower changes were observed in the sample packaged with nylon/LLDPE film. Overall, gelatin film showed excellent oxygen barrier property, which was associated with the retardation of lipid oxidation. The incorporation of oil into gelatin film could lower WVP, but negatively increased oxygen permeability of the resulting film. Thus, the improvement of gelatin film is still required.
\end{abstract}

Keywords Quality changes · Gelatin film · Nylon/LLDPE film · Shrimp cracker

$\begin{array}{ll}\text { Abbreviations } & \\ \text { GF and EF } & \text { Fish gelatin film incorporated without and with palm oil } \\ \text { Nylon/LLDPE } & \text { Nylon/linear low-density polyethylene } \\ \text { FFS } & \text { Film-forming solution } \\ \text { FFD } & \text { Film-forming dispersion } \\ \text { TS } & \text { Tensile strength } \\ \text { EAB } & \text { Elongation at break } \\ \text { WVP } & \text { Water vapour permeability } \\ \text { OTR } & \text { Oxygen transmission rate } \\ \text { PV } & \text { Peroxide value }\end{array}$

K. Nilsuwan · S. Benjakul ( $\bowtie)$

Department of Food Technology, Faculty of Agro-Industry, Prince of Songkla University, Hat Yai, Songkhla 90112,

Thailand

e-mail: soottawat.b@psu.ac.th

T. Prodpran

Department of Material Product Technology, Faculty of Agro-Industry, Prince of Songkla University, Hat Yai, Songkhla 90112, Thailand 
TBARS Thiobarbituric acid reactive substances

$a_{\mathrm{w}} \quad$ Water activity

\section{Introduction}

During the last decade, there has been an increasing interest in edible or biodegradable films based on biopolymers. The main advantage of biopolymers over synthetic polymers is their biodegradability. Biopolymers such as polysaccharides and proteins have been used as biodegradable and/or edible food packaging materials (Artharn et al. 2009; Gennadios et al. 1997). Proteins are important biopolymers possessing good film-forming ability. Among proteins, fish gelatin has been used as film-forming material (Gómez-Guillén et al. 2009). Properties of fish gelatin-based films depend on various factors such as the source of gelatin, concentration of gelatin, plasticisers and substances incorporated into the film-forming solutions (Jongjareonrak et al. 2006; Limpisophon et al. 2010; Tongnuanchan et al. 2012). Gelatin film generally has good mechanical and oxygen barrier properties. However, it has high water absorptivity due to hydrophilicity of gelatin molecules and the presence of hydrophilic plasticisers such as glycerol (Gennadios et al. 1994; Krochta and De Mulder-Johnston 1997; McHugh and Krochta 1994). To improve water vapour barrier properties of the gelatin films, hydrophobic substances such as fats and oils have been added (Bertan et al. 2005; Tongnuanchan et al. 2012). Recently, gelatin film incorporated with palm oil has been prepared by Tongnuanchan et al. (2015) and it had the lowered water vapour permeability. With the improved water vapour barrier property, the gelatin films incorporated with fats and oils could become an environmental friendly edible packaging, which could be used to maintain the quality of foods, especially those prone to the textural changes induced by moisture absorption. Thus, the aim of this work was to study the effect of the gelatin films incorporated without and with palm oil on the quality of shrimp cracker during the extended storage.

\section{Materials and methods}

Materials and chemicals

Glycerol, soy lecithin (HLB = 4.0) and trichloroacetic acid were obtained from Merck (Darmstadt, Germany). Ammonium thiocyanate and 1,1,3,3-tetramethoxypropane (MDA) were purchased from Sigma-Aldrich (St. Louis, MO, USA). All chemicals were of analytical grade. Fish gelatin from tilapia skin $(\sim 240$ bloom $)$ was procured from Lapi Gelatine S.p.A (Empoli, Italy). Palm oil was obtained from OLEEN Company Limited (Bangkok, Thailand).

Preparation of films from fish gelatin incorporated without and with palm oil

\section{Preparation of film-forming solution and dispersion}

Film-forming solution and dispersion were prepared according to the method of Tongnuanchan et al. (2015) with slight modifications. Gelatin $(3.5 \mathrm{~g})$ was dissolved in $90 \mathrm{~mL}$ of distilled water and then heated at $70{ }^{\circ} \mathrm{C}$ for $30 \mathrm{~min}$. Glycerol was added into solution to obtain the concentration of $30 \mathrm{~g} / 100 \mathrm{~g}$ gelatin. The mixture was stirred using a magnetic stirrer for $5 \mathrm{~min}$. The resulting solution was termed as 'film-forming solution, FFS'. For another portion of gelatin solution, glycerol was added to gelatin solution at the level of $10 \mathrm{~g} / 100 \mathrm{~g}$ protein. Palm oil was mixed with soy lecithin at a level of $50 \mathrm{~g} / 100 \mathrm{~g}$ palm oil and then transferred into the prepared gelatin solution to obtain the palm oil concentration of $75 \mathrm{~g} / 100 \mathrm{~g}$ protein. The volume was adjusted to $100 \mathrm{~mL}$ using distilled water. The mixture was homogenised at a speed of 22,000 rpm for 3 min using a rotor-stator homogeniser (IKA Labortechnik homogeniser, Selangor, Malaysia). The coarse emulsion was passed through a Microfluidiser (Model HC-5000, Microfluidiser, Newton, MA, USA) at 20.68 MPa for two 
passes. Fine emulsion was referred to as 'film-forming dispersion, FFD'. Both FFS and FFD were subjected to film preparation.

\section{Film casting and drying}

Prior to casting, FFS and FFD were subjected to air removal by a vacuum pump (Diaphragm vacuum pump, Wertheim, Germany) for $30 \mathrm{~min}$ at room temperature. FFS or FFD $(4 \mathrm{~mL})$ were cast onto a rimmed silicone resin plate $\left(50 \times 50 \mathrm{~mm}^{2}\right)$ and air-blown for $12 \mathrm{~h}$ at room temperature $\left(28-30{ }^{\circ} \mathrm{C}\right)$ prior to further drying at $25{ }^{\circ} \mathrm{C}$ and $50 \pm 5 \%$ relative humidity (RH) for $24 \mathrm{~h}$ in an environmental chamber (WTB Binder, Tuttlingen, Germany). The resulting films were manually peeled off and subsequently analysed.

\section{Determination of film properties}

Film thickness The thickness of film was measured using a micrometer (Mitutoyo, Model ID-C112PM, Serial No. 00320, Mitutoyo Corp., Kawasaki-shi, Japan). Five random locations around each film of ten film samples were used for determination of average thickness.

Mechanical properties Prior to testing, films were conditioned for $48 \mathrm{~h}$ at $25{ }^{\circ} \mathrm{C}$ and $50 \pm 5 \% \mathrm{RH}$. Tensile strength (TS) and elongation at break (EAB) were determined as described by Iwata et al. (2000) using the Universal Testing Machine (Lloyd Instrument, Hampshire, UK) equipped with tensile load cell of $100 \mathrm{~N}$. Ten samples $\left(2 \times 5 \mathrm{~cm}^{2}\right)$ with an initial grip length of $3 \mathrm{~cm}$ were used for testing. Cross-head speed was set at $30 \mathrm{~mm} / \mathrm{min}$.

Water vapour permeability (WVP) WVP was measured using a modified ASTM method (ASTM 1989) as modified by Shiku et al. (2004). The films were sealed on an aluminium permeation cup containing dried silica gel $(0 \% \mathrm{RH})$ with silicone vacuum grease and a rubber gasket to hold the films in place. The cups were placed in a desiccator containing the distilled water at $30{ }^{\circ} \mathrm{C}$. The cups were weighed at 1 -h intervals over a $10-\mathrm{h}$ period. WVP of the film was calculated as follows:

$$
\mathrm{WVP}(\mathrm{g} / \mathrm{m} \mathrm{s} \mathrm{Pa})=\frac{w l}{A t\left(P_{2}-P_{1}\right)}
$$

where $w$ is the weight gain of the cup (g); $l$ is the film thickness (m); $A$ is the exposed area of film $\left(\mathrm{m}^{2}\right) ; t$ is the time of gain (s); $P_{2}-P_{1}$ is the vapour pressure difference across the film $\left(4242.31 \mathrm{~Pa}\right.$ at $\left.30{ }^{\circ} \mathrm{C}\right)$.

Oxygen transmission Oxygen transmission rate (OTR) of films was measured according to the ASTM D3985-05 method. An Oxygen Permeation Analyser (Illinois model 8000, Illinois Instruments Inc., USA) was used to measure oxygen transmission rates through the film. Each film was placed on a stainless steel mask. The mask was then placed in a test cell and exposed to an oxygen atmosphere flow on one side and a nitrogen atmosphere flow on the other. Oxygen transmission rates were measured at $25 \pm 1{ }^{\circ} \mathrm{C}$ and $50 \pm 2 \% \mathrm{RH}$. The film was allowed to equilibrate for $10 \mathrm{~h}$ before measurements.

\section{Preparation of shrimp cracker}

Dried shrimp crackers were obtained from a local market in Songkhla, Thailand. They had an average diameter of $5 \mathrm{~mm}$ with thickness of $1.5 \mathrm{~mm}$. Crackers were fried using an electric deep fryer containing $4 \mathrm{~L}$ of frying oil. Palm oil used as a frying medium was preheated to $180{ }^{\circ} \mathrm{C}$ before frying. Samples were placed in the frying basket and immersed into the oil for $30 \mathrm{~s}$ until samples are completely puffed. Thereafter, fried samples were placed on the screen to drain the oil for $5 \mathrm{~min}$. The fried shrimp cracker was blotted with paper towels to remove an excess oil on the surface and allowed to cool at room temperature $\left(26-28{ }^{\circ} \mathrm{C}\right)$, approximately 15 min before being packaged. 
Study on quality changes of fried shrimp cracker during storage

Fried shrimp cracker $(1.4 \mathrm{~g})$ was placed into an aluminium cup and covered with fish gelatin films incorporated without and with palm oil or nylon/LLDPE film. Fried shrimp cracker stored in aluminium cup without packaging was prepared as the control. The samples were stored at $28 \pm 0.5{ }^{\circ} \mathrm{C}$ and $65 \pm 5 \% \mathrm{RH}$. Shrimp cracker samples were taken every 3 days for totally 15 days for analyses.

\section{Moisture content and water activity}

Moisture content was determined by the method of AOAC (2000). Water activity $\left(a_{\mathrm{w}}\right)$ was measured using a water activity meter (4TEV, Aqualab, Pullman, WA, USA).

\section{Peroxide value}

Peroxide value (PV) was determined as per the method of Richards and Hultin (2000) with a slight modification. Ground shrimp cracker $(1 \mathrm{~g})$ was homogenised at a speed of 13,500 rpm for 2 min in $11 \mathrm{~mL}$ of chloroform/methanol (2:1, w/v). Homogenate was filtered using Whatman No. 1 filter paper. Two millilitres of $\mathrm{NaCl}(5 \mathrm{~g} / \mathrm{L})$ were added to $7 \mathrm{~mL}$ of the filtrate. The mixture was vortexed at a moderate speed for $30 \mathrm{~s}$ and then centrifuged at $3000 \times g$ for 3 min to separate the sample into two phases. Two millilitres of cold chloroform/methanol mixture (2:1) were added to $3 \mathrm{~mL}$ of the lower phase. Twenty-five microlitres of ammonium thiocyanate and $25 \mu \mathrm{L}$ of iron(II) chloride were added to the mixture (Shanta and Decker 1994). Reaction mixture was allowed to stand for $20 \mathrm{~min}$ at room temperature prior to reading the absorbance at $500 \mathrm{~nm}$. A standard curve was prepared using cumene hydroperoxide at a concentration range of $0.5-50 \mathrm{ppm}$. PV was expressed as mg cumene hydroperoxide/ $\mathrm{kg}$ sample.

\section{Thiobarbituric acid-reactive substances (TBARS)}

TBARS values were determined as described by Buege and Aust (1978). Ground shrimp cracker (0.2 g) was mixed with $2.5 \mathrm{~mL}$ of a TBA solution containing $3.75 \mathrm{~g} / \mathrm{L}$ thiobarbituric acid, $150 \mathrm{~g} / \mathrm{L}$ trichloroacetic acid and $0.25 \mathrm{~N} \mathrm{HCl}$. The mixture was heated in a boiling water bath $\left(95-100^{\circ} \mathrm{C}\right)$ for 10 min to develop a pink colour, cooled with running tap water and then sonicated for $30 \mathrm{~min}$, followed by centrifugation at $5000 \times g$ at $25{ }^{\circ} \mathrm{C}$ for $10 \mathrm{~min}$. The absorbance of the supernatant was measured at $532 \mathrm{~nm}$. A standard curve was prepared using 1,1,3,3-tetramethoxypropane (MDA) at the concentration ranging from 0 to $10 \mathrm{ppm}$ and TBARS value was expressed as mg MDA equivalent/kg sample.

\section{Textural properties}

Textural property of shrimp cracker was measured at room temperature by a compressive test using a texture analyser (Stable Micro Systems, Guildford, UK). Ottawa cell with flat square probe was used to determine the crispiness, in which the maximum force required to break the shrimp cracker samples was recorded. Toughness was determined by measuring the area under the curve during compressing. The studies were conducted using a pre-test speed of $1.0 \mathrm{~mm} / \mathrm{s}$, test speed of $2.0 \mathrm{~mm} / \mathrm{s}$, distance of $5.0 \mathrm{~mm}$, and load cell of $50 \mathrm{~kg}$.

Volatile compounds

Volatile compounds in fried shrimp cracker samples were determined using a solid-phase micro-extraction gas chromatography-mass spectrometry (SPME-GC-MS) following the method of Iglesias and Medina (2008) with a slight modification. 
To extract volatile compounds, $1 \mathrm{~g}$ of sample was mixed with $4 \mathrm{~mL}$ of deionised water and stirred continuously to disperse the sample. The mixture was heated at $60{ }^{\circ} \mathrm{C}$ in $20 \mathrm{~mL}$ headspace vial with equilibrium time of $10 \mathrm{~h}$. The SPME fibre (50/30 $\mu \mathrm{m} \mathrm{DVB/Carboxen}{ }^{\mathrm{TM}} / \mathrm{PDMS}$ StableFlex ${ }^{\mathrm{TM}}$ ) (Supelco, Bellefonte, PA, USA) was conditioned at $270{ }^{\circ} \mathrm{C}$ for $15 \mathrm{~min}$ before use and then exposed to the headspace. The 20-mL vial (Agilent Technologies, Palo Alto, CA, USA) containing the sample extract and the volatile compounds were allowed to absorb into the SPME fibre at $60^{\circ} \mathrm{C}$ for $1 \mathrm{~h}$. The volatile compounds were then desorbed in the GC injector port for $15 \mathrm{~min}$ at $270{ }^{\circ} \mathrm{C}$.

GC-MS analysis

GC-MS analysis was performed in a HP 5890 series II gas chromatography (GC) coupled with HP 5972 massselective detector equipped with a splitless injector and coupled with a quadrupole mass detector (Hewlett Packard, Atlanta, GA, USA). Compounds were separated on a HP-Innowax capillary column (Hewlett Packard, Atlanta, GA, USA) $(30 \mathrm{~m} \times 0.25 \mathrm{~mm}$ ID, with film thickness of $0.25 \mu \mathrm{m})$. The GC oven temperature program was: $35{ }^{\circ} \mathrm{C}$ for $3 \mathrm{~min}$, followed by an increase of $3{ }^{\circ} \mathrm{C} / \mathrm{min}$ to $70{ }^{\circ} \mathrm{C}$, then an increase of $10{ }^{\circ} \mathrm{C} /$ min to $200{ }^{\circ} \mathrm{C}$, and finally an increase of $15{ }^{\circ} \mathrm{C} / \mathrm{min}$ to a final temperature of $250{ }^{\circ} \mathrm{C}$ and holding for $10 \mathrm{~min}$. Helium was employed as a carrier gas, with a constant flow of $1 \mathrm{~mL} / \mathrm{min}$. The injector was operated in the splitless mode and its temperature was set at $270{ }^{\circ} \mathrm{C}$. Transfer line temperature was maintained at $260{ }^{\circ} \mathrm{C}$. The quadrupole mass spectrometer was operated in the electron ionisation (EI) mode and source temperature was set at $250{ }^{\circ} \mathrm{C}$. Initially, full scan mode data were acquired to determine appropriate masses for the later acquisition in scan mode under the following conditions: mass range, 25-500 amu and scan rate, $0.220 \mathrm{~s} / \mathrm{scan}$. All the analyses were performed with ionisation energy of $70 \mathrm{eV}$, filament emission current at $150 \mu \mathrm{A}$, and the electron multiplier voltage at $500 \mathrm{~V}$.

\section{Analyses of volatile compounds}

Identification of volatile compounds in the samples was done by consulting ChemStation Library Search (Wiley 275.L). Identification of compounds was performed, based on the retention time and mass spectra in comparison with those of standards from ChemStation Library Search (Wiley 275.L). Quantification limits were calculated to a signal-to-noise $(S / N)$ ratio of 10 . The identified volatile compounds were expressed in the terms of relative abundance.

Statistical analysis

All experiments were run in triplicate with different three lots of films. Data were subjected to analysis of variance (ANOVA) and mean comparisons were carried out by Duncan's multiple range test. Analysis was performed using the SPSS package (SPSS for windows, Inc., Chicago, IL, USA).

\section{Results and discussions}

Properties of different films

Films from fish gelatin incorporated without and with palm oil and nylon/linear low-density polyethylene (nylon/LLDPE) had varying properties as shown in Table 1. Different films showed various thickness. Film from fish gelatin incorporated with palm oil (EF) showed the higher thickness, whilst gelatin film (GF) had the lowest thickness $(p<0.05)$. For tensile strength (TS) and elongation at break (EAB), nylon/LLDPE film had the highest values $(p<0.05)$. When comparing between GF and EF samples, the latter showed the higher TS and EAB than the former $(p<0.05)$. Oil droplet incorporated in matrix might strengthen the resulting films. Oil droplets might reduce the interaction between gelatin chains as indicated by higher EAB. This reduction in protein-protein interaction might take place at appropriate degree, which brought about the increased 
Table 1 Thickness, tensile strength (TS), elongation at break (EAB), water vapour permeability (WVP) and oxygen transmission rate (OTR) of films from fish gelatin incorporated without (GF) and with (EF) palm oil and nylon/linear low-density polyethylene (nylon/LLDPE) film

\begin{tabular}{llllcc}
\hline Films & Thickness $(\mathrm{mm})$ & TS $(\mathrm{MPa})$ & EAB $(\%)$ & WVP $\left(\times 10^{-12} \mathrm{~g} / \mathrm{m} \mathrm{s} \mathrm{Pa}\right)$ & OTR $\left(\mathrm{cc} / \mathrm{m}^{2}\right.$ day $)$ \\
\hline Nylon/LLDPE & $0.080 \pm 0.001^{* \mathrm{~b}}$ & $48.75 \pm 1.06^{\mathrm{a}}$ & $132.5 \pm 3.70^{\mathrm{a}}$ & $0.81 \pm 0.16^{\mathrm{c}}$ & $92.50 \pm 3.70^{\mathrm{a}}$ \\
GF & $0.055 \pm 0.002^{\mathrm{c}}$ & $26.90 \pm 1.19^{\mathrm{c}}$ & $40.17 \pm 1.37^{\mathrm{c}}$ & $23.90 \pm 0.69^{\mathrm{a}}$ & $3.53 \pm 0.28^{\mathrm{c}}$ \\
EF & $0.086 \pm 0.001^{\mathrm{a}}$ & $41.00 \pm 0.47^{\mathrm{b}}$ & $59.65 \pm 1.11^{\mathrm{b}}$ & $4.50 \pm 0.04^{\mathrm{b}}$ & $63.20 \pm 4.42^{\mathrm{b}}$
\end{tabular}

Different superscript lowercase letters in the same column indicate significant differences $(p<0.05)$

* Mean $\pm \operatorname{SD}(n=3)$

extension of film before breaking. Upon film stretching without breaking, gelatin molecule in the film matrix could undergo more orientation, which could withstand more tensile load. This led to the increased strength (i.e. TS) of the palm oil-incorporated gelatin film, compared to control film. For water vapour permeability (WVP), nylon/LLDPE film, which is the synthetic film, had the lowest value $(p<0.05)$. Gelatin film showed a decrease in WVP when oil was incorporated in the film (EF). Oil droplets distributed in film acted as barrier against water vapour adsorption and migration through the film. Overall, film from nylon/LLDPE had the highest oxygen transmission rate (OTR) $(p<0.05)$. In general, protein-based film showed higher oxygen barrier properties than the plastic films such as nylon/metallocene-catalysed linear low-density polyethylene (nylon/mLLDPE), low-density polyethylene (LDPE) and high-density polyethylene (HDPE) films (Cho et al. 2010; Rhim et al. 2006). Amongst all films, GF had the lowest OTR $(p<0.05)$. Gelatin-based film has been reported to possess excellent oxygen barrier property (Jongjareonrak et al. 2006). It was noted that the incorporation of oil increased OTR of gelatin film. When oil was added, the matrix was disconnected and the hydrophobicity of gelatin film generally increased, which could increase adsorption or solubility of oxygen, a non-polar molecule, in the film. This brought about the lowering of oxygen barrier property of the film. The increasing oxygen transmission rate of films incorporated with oil was related to the microstructural changes, in which the film became more porous with the addition of oil (Altiok et al. 2010).

Quality changes of shrimp cracker during storage as affected by various films

\section{Moisture content and water activity}

Moisture contents of fried shrimp cracker kept in aluminium cup covered with fish gelatin films incorporated without (GF) and with palm oil (EF) in comparison with nylon/linear low-density polyethylene (nylon/ LLDPE) film during 15 days of storage are shown in Fig. 1a. The initial moisture content of cracker was $1.13 \%$. In general, the moisture content of fried shrimp cracker in aluminium cup covered with all films drastically increased within the first 3 days of storage $(p<0.05)$. The moisture content was increased to a higher extent for the sample packaged in both gelatin films (GF and EF) than that found in sample packaged in nylon/LLDPE film throughout the 15 days $(p<0.05)$. At 15 days of storage, samples packaged with GF, EF and nylon/LLDPE film showed the increase in moisture content by $8.40,8.46$, and 4.54 -fold, respectively. The result was in agreement with the lowest WVP of nylon/LLDPE film (Table 1). When comparing moisture content of shrimp cracker covered with GF and EF, the former showed the higher moisture content $(p<0.05)$. The result confirmed that the incorporation of oil could lower the migration of water vapour to the sample. This was in accordance with the lower WVP of EF in comparison with GF (Table 1).

For water activity (Fig. 1b), fried shrimp cracker covered with EF showed lower water activity than those covered with GF during 3-9 days of storage $(p<0.05)$. Initial water activity of fried crackers was 0.22 . Much lower water activity was also found in sample packaged with nylon/LLDPE film throughout the 15 days of storage $(p<0.05)$. The result indicated that water vapour barrier property of gelatin film was lower than that of nylon/LLDPE film. Generally, water vapour barrier property of gelatin film was poorer than that of other biopolymer films, especially for non-hydrophilic material or synthetic polymer, due to the hydrophilic nature of gelatin and hydrophilic plasticiser required for film preparation (Limpisophon et al. 2009). The increase in moisture content and water activity of fried shrimp cracker was due to the diffusion of water vapour from the 

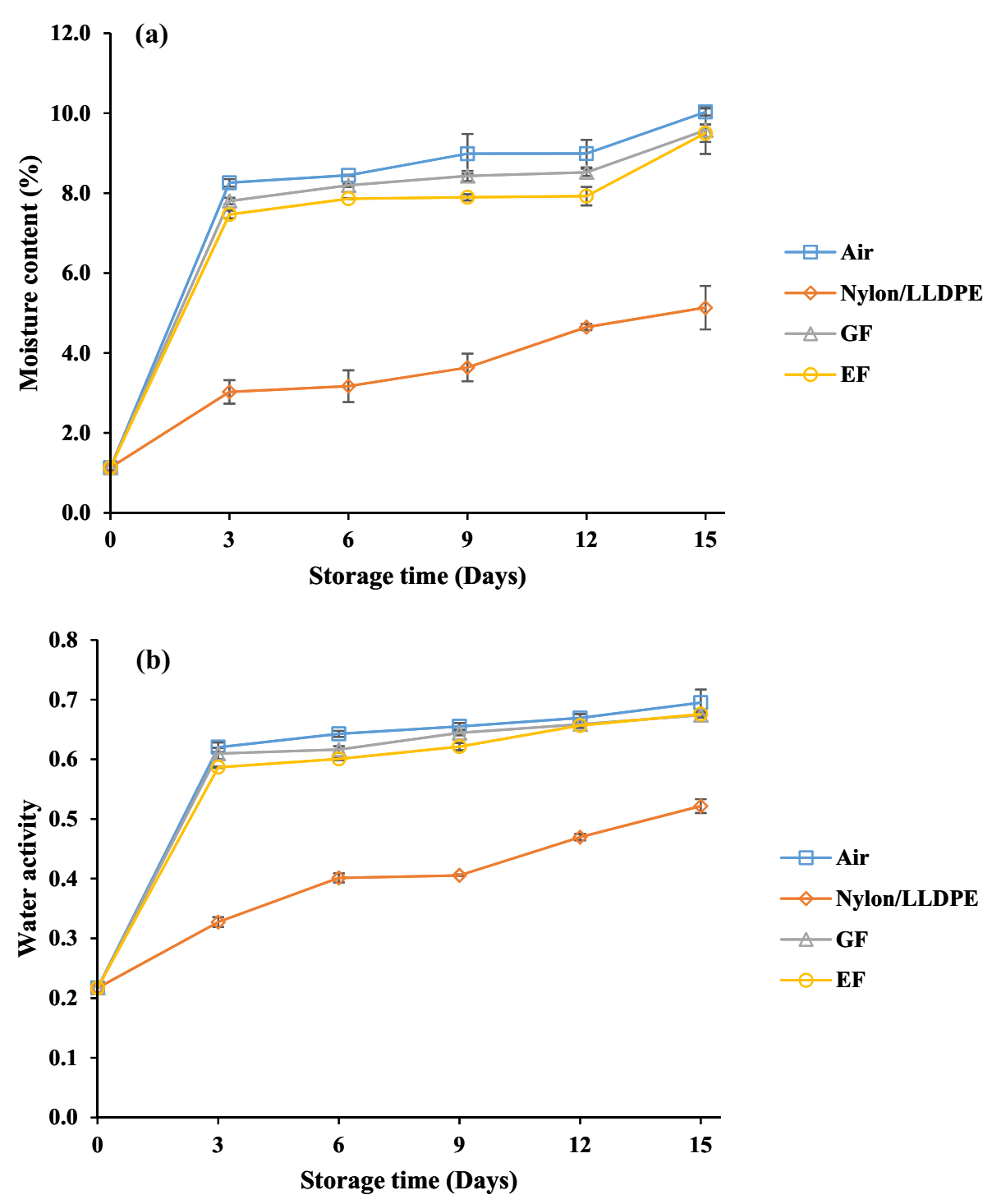

Fig. 1 Changes in moisture content (a) and water activity (b) of fried shrimp cracker packaged with GF, EF and nylon/LLDPE films during storage of 15 days at $28 \pm 0.5{ }^{\circ} \mathrm{C}$ and $65 \pm 5 \% \mathrm{RH}$. Air fried shrimp cracker without packaging. Bars represent the standard deviation $(n=3)$. $G F$ and $E F$ fish gelatin film incorporated without and with palm oil, respectively, nylon/LLDPE nylon/linear low-density polyethylene film

surrounding atmosphere through the packaging material. Generally, the incorporation of hydrophobic substances such as oil improved the water vapour barrier property of gelatin film (Tongnuanchan et al. 2015). Therefore, the incorporation of palm oil could improve the water vapour barrier property of gelatin film, as evidenced by the lower moisture content and water activity of fried shrimp cracker during the storage. Amongst all samples, that stored in air (without film covering) had the higher moisture content and water activity. Therefore, films, either synthetic or gelatin films, were able to serve as the barrier against water vapour migration, in which the quality changes of cracker could be retarded.

\section{Peroxide value and TBARS}

Lipid oxidation of fried shrimp cracker stored in aluminium cup covered with GF and EF in comparison with nylon/LLDPE film during the 15 days of storage was monitored as shown in Fig. 2a, b. PV of samples covered with either GF or EF increased during the 15 days of storage $(p<0.05)$. During storage, the samples packaged with nylon/LLDPE film had no difference in PV, compared with those packaged with GF 

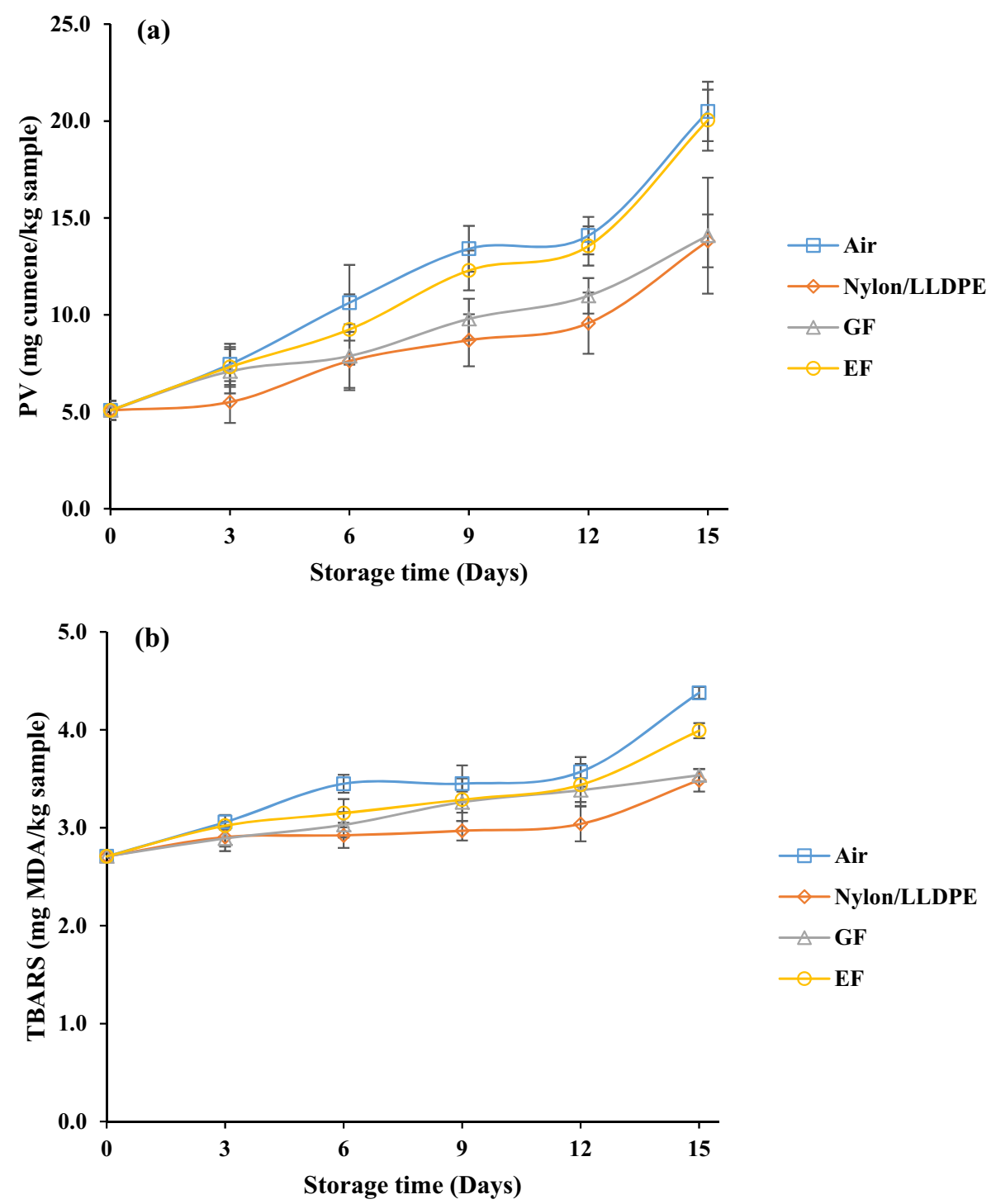

Fig. 2 Changes in peroxide value (a) and TBARS (b) of fried shrimp cracker packaged with GF, EF and nylon/LLDPE films during storage of 15 days at $28 \pm 0.5{ }^{\circ} \mathrm{C}$ and $65 \pm 5 \% \mathrm{RH}$. Air fried shrimp cracker without packaging. Bars represent the standard deviation $(n=3)$. $G F$ and $E F$ fish gelatin film incorporated without and with palm oil, respectively, nylon/LLDPE nylon/linear low-density polyethylene film

$(p>0.05)$. It was found that sample covered with EF had similar PV to the control throughout the storage $(p>0.05)$. Oxidative changes in crackers were initiated by the formation of free radicals, the precursors for the hydroperoxides, which were the primary oxidation products (Maisuthisakul et al. 2007). Crackers are susceptible to lipid oxidation due to the large surface area in contact with the air, in which carbonyl compounds and hydroperoxides are generated (Noomhorm et al. 1997). Due to the excellent oxygen barrier property of GF, the PV was expected to be lower in the sample covered with GF. Nevertheless, GF had the poorer WVP than nylon/LLDPE film. As a consequence, the water in the cracker was increased. The higher amount of water might facilitate the movement of reactants, especially prooxidant. Thus, the oxidative reaction was increased although the amount of oxygen used for oxidation was limited.

Continuous increases of TBARS value were observed in all samples throughout the storage of 15 days. Lower TBARS values were obtained in sample stored with nylon/LLDPE film during 9-12 days of storage $(p<0.05)$. Lipid oxidation can be accelerated at high RH since more water molecules can act as reaction media (Partanen et al. 2008). As the moisture content and water activity of all samples increased during the 15 days of storage, lipid oxidation could be promoted, especially for the samples covered with EF. However, 
there was no difference in TBARS value between sample covered with GF and nylon/LLDPE films at day 15 $(p>0.05)$. The result was in agreement with PV. Thus, packaging materials used was a prime factor affecting water vapour and oxygen permeability, thereby influencing oxidative stability. The result suggested that the incorporation of palm oil into gelatin could lower water vapour migration, but it decreased the barrier property toward oxygen molecule (Table 1).

\section{Textural properties}

Crispiness (force necessary to break a product) and toughness (area under the curve during compressing) of fried shrimp cracker stored in aluminium cup, covered with GF and EF in comparison with nylon/LLDPE film during 15 days of storage are shown in Fig. 3a, b. Physical properties, such as density, shrinkage and porosity, are the main factors affecting the texture and transport phenomena of fried foods (Ziaiifar et al. 2010). Crispiness is related to the deformation and fracturing of subsequent layers in a cell structure of food products (Luyten et al. 2004). Crispiness of samples packaged with all films sharply decreased with the first 3 days of
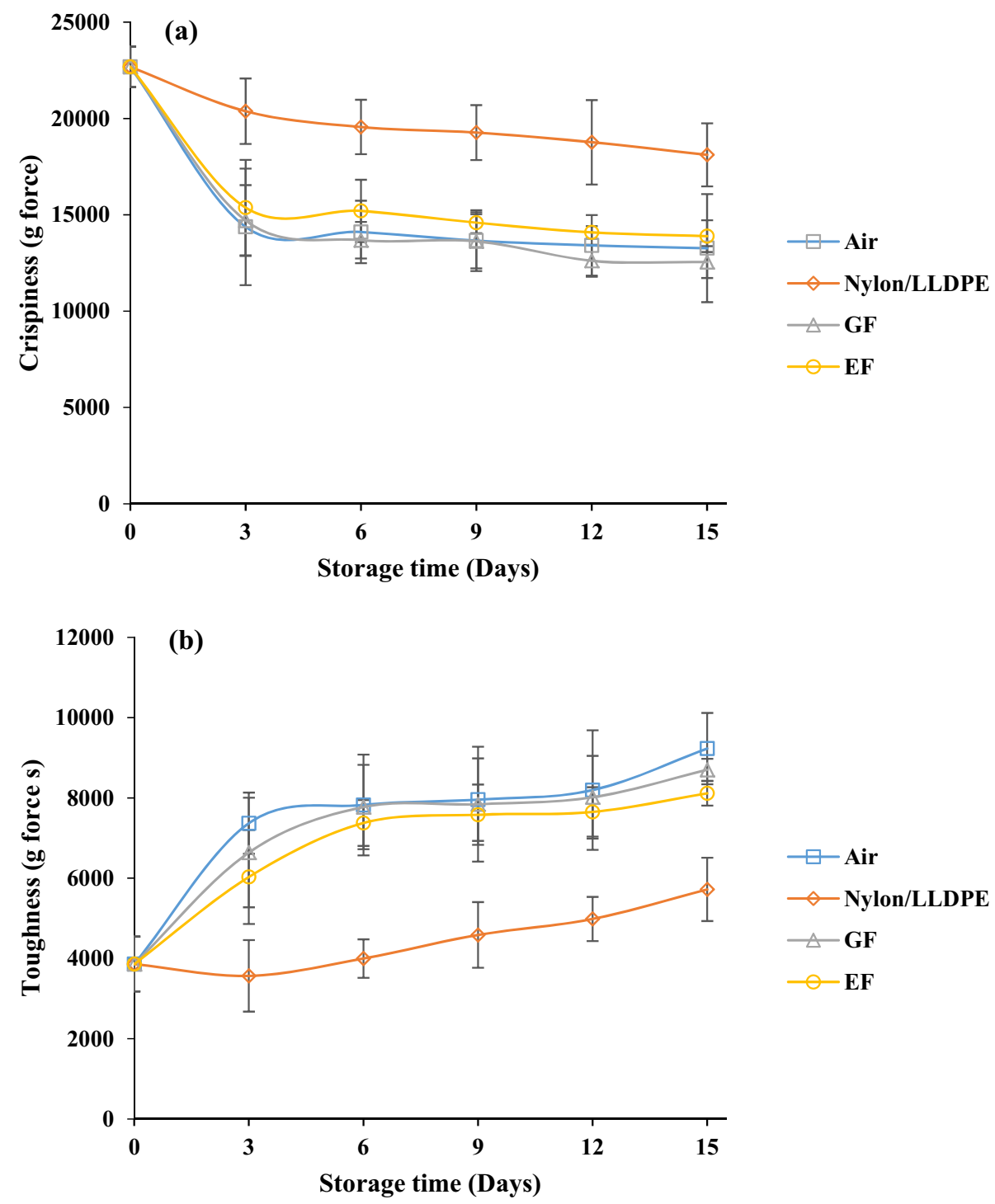

Fig. 3 Changes in crispiness (a) and toughness (b) of fried shrimp cracker packaged with GF, EF and nylon/LLDPE films during storage of 15 days at $28 \pm 0.5{ }^{\circ} \mathrm{C}$ and $65 \pm 5 \% \mathrm{RH}$. Air fried shrimp cracker without packaging. Bars represent the standard deviation $(n=3)$. $G F$ and $E F$ fish gelatin film incorporated without and with palm oil, respectively, nylon/LLDPE nylon/linear low-density polyethylene film 
storage $(p<0.05)$, except that covered with nylon/LLDPE film. Similar rate of decrease in crispiness was observed during 3-15 days of storage. During storage, shrimp cracker covered with nylon/LLDPE film showed the higher crispiness than others $(p<0.05)$. No difference in crispiness between samples packaged with GF and EF was observed $(p>0.05)$. Crispiness of sample covered with gelatin films was similar to that of the control. On the other hand, the toughness of shrimp cracker samples covered with GF and EF and that kept in air markedly increased within the first 3 day of storage $(p<0.05)$. No change in toughness of sample packaged with nylon/LLDPE film was obtained during the first 6 days of storage $(p>0.05)$. When storage time was increased, the water vapour might migrate through the films and contact with the sample surface to a higher extent. Water more likely reduced the strength of air cell structure of cracker (Luyten et al. 2004). Water might fluidise the cracker network, where it became tougher in texture. The change was coincidental with the increase in toughness of cracker. Thus, packaging with the ability in lowering water vapour migration was required for crispy cracker, in which textural property could be maintained. Although the incorporation of palm oil into gelatin film in this study could lower WVP of resulting film to some degree, the film still showed the lower barrier property toward water vapour, in comparison with the commercial nylon/LLDPE film.

\section{Volatile compounds}

Selected volatile compounds in freshly fried shrimp cracker and those stored in aluminium cup covered with GF and EF in comparison with nylon/LLDPE film after 15 days of storage are shown in Table 2. At day 0, fried shrimp cracker contained some volatile compounds including aldehyde (hexanal, $n$-nonanal and 2-decenal), alcohol (1-pentanol and 2-Furanmethanol), nitrogen-containing compounds (2,6-dimethylpyrazine), and noncyclic hydrocarbons ( $n$-tridecane and $n$-undecane). The result suggested that shrimp cracker underwent lipid oxidation to some degree during frying. After 15 days of storage, volatile compounds were also found in all fried shrimp cracker, but the abundance and types of compounds varied. Aldehydes have been used as the index of lipid oxidation in a number of foods, because they possess low threshold values and are

Table 2 Selected volatile compounds in freshly prepared shrimp cracker and those stored with different films after 15 days

\begin{tabular}{|c|c|c|c|c|c|}
\hline \multirow[t]{2}{*}{ Volatile compounds } & \multirow[t]{2}{*}{ Day 0} & \multicolumn{4}{|c|}{ Day 15} \\
\hline & & Air & Nylon/LLDPE & GF & $\mathrm{EF}$ \\
\hline \multicolumn{6}{|l|}{ Aldehydes } \\
\hline Hexanal & 0.7 & 25.7 & 2.6 & 3.9 & 16.1 \\
\hline$n$-Nonanal & 0.5 & 13.2 & 3.9 & 1.8 & 12.3 \\
\hline 2-Decenal & 2.8 & 8.1 & 2 & 1.9 & 7.5 \\
\hline 2,4-Decadienal & ND & 3.2 & 0.8 & 0.4 & 3 \\
\hline \multicolumn{6}{|l|}{ Alcohols } \\
\hline 1-Methoxy-2-propanol & ND & 7.1 & ND & ND & ND \\
\hline 1-Pentanol & 1.9 & 5.8 & 2.5 & 2.6 & 2.8 \\
\hline 2-Furanmethanol & 0.3 & 1.5 & 0.4 & 0.5 & 1.0 \\
\hline \multicolumn{6}{|c|}{ Nitrogen-containing compounds } \\
\hline Methylpyrazine & ND & 0.8 & ND & ND & ND \\
\hline 2,5-Dimethylpyrazine & ND & 7 & 4.4 & 5 & 4.9 \\
\hline 2,6-Dimethylpyrazine & 2.5 & 1.3 & 0.5 & 0.5 & 0.6 \\
\hline Ethylpyrazine & ND & 1.1 & 0.5 & 0.8 & 0.8 \\
\hline \multicolumn{6}{|l|}{ Noncyclic hydrocarbons } \\
\hline Heptane & ND & 5.1 & 0.8 & 3.8 & 5.0 \\
\hline$n$-Tridecane & 0.4 & 9.5 & 8.8 & 9.3 & 9.2 \\
\hline$n$-Dodecane & ND & 19.6 & 18.4 & 19.0 & 20.2 \\
\hline$n$-Undecane & 2.8 & 19.0 & 13.0 & 18.1 & 18.8 \\
\hline
\end{tabular}

$N D$ non-detectable, $G F$ and $E F$ fish gelatin film incorporated without and with palm oil, respectively, nylon/LLDPE nylon/linear low-density polyethylene film, Air fried shrimp cracker without packaging

* Values are expressed as abundance $\left(\times 10^{9}\right)$ 
the major contributors to off-odour and off-flavour (Ross and Smith 2006). Numerous aldehydes produced during oxidation included octanal, nonanal, pentanal, hexanal, etc. (Ross and Smith 2006). Amongst all aldehydic compounds, hexanal and $n$-nonanal were found as the major aldehydes in all stored shrimp cracker samples, followed by 2-decenal and 2,4-decadienal (Table 2). Sample stored in air had the highest abundance of all aldehydes. It was noted that sample packaged with GF showed similar profile to that stored with nylon/ LLDPE film. Nevertheless, some differences in hexanal and $n$-nonanal were noticeable. This reconfirmed the excellent oxygen barrier property of GF film (Table 1). Alcohols are the secondary products produced by the decomposition of hydroperoxide (Eymard et al. 2009). The 1-pentanol and 2-furanmethanol were found in shrimp cracker samples (Table 2). All shrimp cracker samples after 15 days of storage showed the higher abundance of those alcoholic compounds than freshly prepared sample. It was postulated that higher lipid oxidation and greater decomposition of hydroperoxide occurred. Higher abundance of volatile lipid oxidation products found in fried shrimp cracker without packaging correlated well with high TBARS value as shown in Fig. 2b. 1-Methoxy-2-propanol was found only in sample stored in air after 15 days of storage. Four nitrogencontaining compounds mainly pyrazine derivatives, were found in fried shrimp cracker. The 2,5-dimethylpyrazine was detected in all samples after 15 days of storage. Conversely, 2,6-dimethylpyrazine was formed only in freshly prepared sample (day 0). Pyrazines were reported to be formed by Maillard reaction from degradations of various nitrogen sources such as amino acids (Jaffrès et al. 2011). Methylpyrazine was found only in fried shrimp cracker kept without packaging (air), whilst ethylpyrazine was detected only in the stored shrimp cracker. The presence of pyrazine indicated that browning reaction mediated by Maillard reaction occurred in shrimp cracker samples during the 15 days of storage. Furthermore, some hydrocarbon compounds including heptane, $n$-tridecane, $n$-dodecane and $n$-undecane were found in fried shrimp cracker after 15 days of storage. The abundance of those compounds increased after 15 days of storage. Alkanes are mainly formed from lipid auto-oxidation of fatty acids released from triglycerides (Latorre-Moratalla et al. 2011). Based on volatile compounds, fried shrimp cracker stored with different packaging showed varying volatile compounds.

\section{Conclusion}

Fish gelatin films incorporated with palm oil could lower the increase in moisture content and water activity of fried shrimp cracker to some extent, but its capability was still lower than nylon/LLDPE film. The preventive effect toward lipid oxidation of films from fish gelatin was equivalent to nylon/LLDPE film. However, fish gelatin film could not maintain the textural property of cracker during storage. Therefore, the improvement of barrier property against water and oxygen of fish gelatin film is still needed.

Author contribution SB developed the initial idea and designed the study. KN was responsible for conducting experiments and analysis of data. SB and $\mathrm{KN}$ carried out the analytical work. KN wrote the manuscript with assistance from SB and TP. SB and TP read and approved the final manuscript.

Acknowledgments The authors would like to thank the Graduate School of Prince of Songkla University, Thailand, for the financial support. The TRF Distinguished Research Professor Grant was also acknowledged.

Compliance with ethical standards

Conflict of interest The authors declare that they have no competing interests.

Open Access This article is distributed under the terms of the Creative Commons Attribution 4.0 International License (http:// creativecommons.org/licenses/by/4.0/), which permits unrestricted use, distribution, and reproduction in any medium, provided you give appropriate credit to the original author(s) and the source, provide a link to the Creative Commons license, and indicate if changes were made.

\section{References}

Altiok D, Altiok E, Tihminlioglu F (2010) Physical, antibacterial and antioxidant properties of chitosan films incorporated with thyme oil for potential wound healing applications. J Mater Sci Mater Med 21:2227-2236 
AOAC (2000) Official method of analysis. Association of Official Chemists, Washington

Artharn A, Prodpran T, Benjakul S (2009) Round scad protein-based film: storage stability and its effectiveness for shelf-life extension of dried fish powder. LWT Food Sci Technol 42:1238-1244

ASTM (1989) Standard test methods for water vapor transmission of materials. Standard designation E96-E80. In: Annual book of ASTM standards. American Society for Testing and Materials, Philadelphia, PA, pp 730-739

Bertan LC, Tanada-Palmu PS, Siani AC, Grosso CRF (2005) Effect of fatty acids and 'Brazilian elemi' on composite films based on gelatin. Food Hydrocolloid 19:73-82

Buege JA, Aust SD (1978) Microsomal lipid peroxidation. Methods Enzymol 52:302-310

Cho SY, Lee SY, Rhee C (2010) Edible oxygen barrier bilayer film pouches from corn zein and soy protein isolate for olive oil packaging. LWT Food Sci Technol 43:1234-1239

Eymard S, Baron CP, Jacobsen C (2009) Oxidation of lipid and protein in horse mackerel (Trachurus trachurus) mince and washed minces during processing and storage. Food Chem 114:57-65

Gennadios A, McHugh TH, Weller CL, Krochta JM (1994) Edible coatings and films based on proteins. In: Krochta JM, Baldwin EA, Nisperos-Carriedo M (eds) Edible coatings and films to improve food quality. Technomic Publishing Company, Inc, Lancaster, PA, pp 201-277

Gennadios A, Hanna MA, Kurth LB (1997) Application of edible coatings on meats, poultry and seafoods: a review. LWT Food Sci Technol 30:337-350

Gómez-Guillén MC, Pérez-Mateos M, Gómez-Estaca J, López-Caballero E, Giménez B, Montero P (2009) Fish gelatin: a renewable material for developing active biodegradable films. Trends Food Sci Technol 20:3-16

Iglesias J, Medina I (2008) Solid-phase microextraction method for the determination of volatile compounds associated to oxidation of fish muscle. J Chromatogr A 1192:9-16

Iwata KI, Ishizaki SH, Handa AK, Tanaka MU (2000) Preparation and characterization of edible films from fish water-soluble proteins. Fish Sci 66:372-378

Jaffrès E, Lalanne V, Macé S, Cornet J, Cardinal M, Sérot T, Dousset X, Joffraud J-J (2011) Sensory characteristics of spoilage and volatile compounds associated with bacteria isolated from cooked and peeled tropical shrimps using SPME-GC-MS analysis. Int J Food Microbiol 147:195-202

Jongjareonrak A, Benjakul S, Visessanguan W, Prodpran T, Tanaka M (2006) Characterization of edible films from skin gelatin of brownstripe red snapper and bigeye snapper. Food Hydrocolloid 20:492-501

Krochta JM, De Mulder-Johnston C (1997) Edible and biodegradable polymer films: challenges and opportunities. Food Technol 51:61-72

Latorre-Moratalla ML, Bosch-Fusté J, Bover-Cid S, Aymerich T, Vidal-Carou MC (2011) Contribution of enterococci to the volatile profile of slightly-fermented sausages. LWT Food Sci Technol 44:145-152

Limpisophon K, Tanaka M, Weng W, Abe S, Osako K (2009) Characterization of gelatin films prepared from under-utilized blue shark (Prionace glauca) skin. Food Hydrocolloid 23:1993-2000

Limpisophon K, Tanaka M, Osako K (2010) Characterisation of gelatin-fatty acid emulsion films based on blue shark (Prionace glauca) skin gelatin. Food Chem 122:1095-1101

Luyten H, Plijter JJ, Van Vliet TON (2004) Crispy/crunchy crusts of cellular solid foods: a literature review with discussion. J Texture Stud 35:445-492

Maisuthisakul P, Gordon MH, Pongsawatmanit R (2007) Enhancing the oxidative stability of rice crackers by addition of the ethanolic extract of phytochemicals from Cratoxylum formosum Dyer. Asia Pac J Clin Nutr 16:37-42

McHugh TH, Krochta JM (1994) Water vapor permeability properties of edible whey protein-lipid emulsion films. J Am Oil Chem Soc 71:307-312

Noomhorm A, Kongseree N, Apintanapong M (1997) Effect of aging on the quality of glutinous rice crackers. Cereal Chem 74:12-15

Partanen R, Raula J, Seppanen R, Buchert J, Kauppinen E, Forssell P (2008) Effect of relative humidity on oxidation of flaxseed oil in spray dried whey protein emulsions. J Agric Food Chem 56:5717-5722

Rhim J-W, Mohanty KA, Singh SP, Ng PKW (2006) Preparation and properties of biodegradable multilayer films based on soy protein isolate and poly (lactide). Ind Eng Chem Res 45:3059-3066

Richards MP, Hultin HO (2000) Effect of $\mathrm{pH}$ on lipid oxidation using trout hemolysate as a catalyst: a possible role for deoxyhemoglobin. J Agric Food Chem 48:3141-3147

Ross CF, Smith DM (2006) Use of volatiles as indicators of lipid oxidation in muscle foods. Compr Rev Food Sci Food Saf 5:18-25

Shanta NC, Decker EA (1994) Rapid, sensitive, iron-based spectrophotometric methods for determination of peroxide values of food lipids. J AOAC Int 77:421-424

Shiku Y, Hamaguchi PY, Benjakul S, Visessanguan W, Tanaka M (2004) Effect of surimi quality on properties of edible films based on Alaska pollack. Food Chem 86:493-499

Tongnuanchan P, Benjakul S, Prodpran T (2012) Properties and antioxidant activity of fish skin gelatin film incorporated with citrus essential oils. Food Chem 134:1571-1579

Tongnuanchan P, Benjakul S, Prodpran T, Nilsuwan K (2015) Emulsion film based on fish skin gelatin and palm oil: physical, structural and thermal properties. Food Hydrocolloid 48:248-259

Ziaiifar AM, Courtois F, Trystram G (2010) Porosity development and its effect on oil uptake during frying process. J Food Process Eng 33:191-212 